\title{
HUMUS REMOVAL EFFICIENCY FROM RIVER WATER BY A VARIETY OF METHODS AND PHYCICAL-CHEMICAL PROPERTIES OF ISOLATED HUMUS
}

\author{
Janusz Pempkowiak \\ Technical University of Koszalin, Poland
}

\begin{abstract}
The efficiency of humic substances isolation, from river water was assessed utilizing a variety of techniques. Selected physical and chemical characteristics of isolates were analysed, in order to compare properties of the isolated material.

It was found that the recovery of dissolved humus depends on a method employed for isolation. Thus it was equal to $70 \%$ (extraction), $87 \%$ (reverse osmosis), $33 \%$ (coprecipitation), $76 \%$ (anion exchange), and ranged from $40 \%$ to $87 \%$ for a variety of solid sorbents. The efficiency of sorption/desertion on solid sorbents, measured as recovery of coloured substances (\%), was equal to: activated carbon (100/40), weak anion exchanger DEAE $\left(\mathrm{Cl}^{-}\right)$(95/95), styrene-divinylbenzene Amberlite XAD-2 (96/87), poliacrylamide Amberlite XAD-8 (98/87).

\section{Introduction}

Humic substances are a major fraction of organic matter in soils, sediments and water (Aiken, 1985 ). They draw attention due to the influence on processes taking place in the environment. Due to the presence of dissolved and coloidal humic substances excess colour and turbidity of surface water develops, features essential in water treatment (Gjessing et al., 1998). Investigations of humic substances dissolved in both river and lake waters are difficult because of the substances small contribution to dry residue left after water evaporation (most often less then $0.5 \%$ of dry matter content). The difficulty may be overcome when acids are isolated from water and experiments are carried out in model aqueous solutions. Several isolation procedures have been applied to isolation of humic substances from fresh and saline waters. They include reverse osmosis, sorption on solid sorbents (activated carbon, nylon, macroporous resins), extraction (of both dry residue or aqueous solution), and weak anion exchangers (Aiken, 1985; Pempkowiak, 1989). Application of such a diversified separation techniques most likely leads to quantitative and qualitative differences in the isolated material.

In this paper efficiencies of several isolation procedures of humic substances were tested. The quality of the isolated material was assessed basing on absorption spectra (UV, VIS, IR, ${ }^{1} \mathrm{H}-\mathrm{NMR}$ ), elemental composition (C, H, N, S), and molecular weight distribution.
\end{abstract}




\section{Experimental}

Collecting and preparation of water samples. Water samples were collected from the Vistula river some $15 \mathrm{~km}$ upstream from the mouth. They were filtered through precombusted glass fibre filters (GF/F Whatman) on the day of collection, and used for isolation of humic substances. Several isolation procedures were applied.

Reverse osmosis. Water was passed through cation exchange resin Rexyn $101\left(\mathrm{Na}^{+}\right)$, followed by Browen-120 membranes until concentration factor 1:250 was reached. Permeat was discarded, while the concentrate was further concentrated in a rotary evaporator.

$D E A E$ anionite. Water was passed through a glass column $\left(30 \times 3 \mathrm{~cm}^{2}\right)$ filled with DEAE $\left(\mathrm{Cl}^{-}\right)$ anionite exchanger. The sorbed humic substances were desorbed with $0.1 \mathrm{~mol} / \mathrm{dm}^{3} \mathrm{NH}_{3} \cdot \mathrm{H}_{2} \mathrm{O}$.

Amberlite $X A D-2$ and $X A D-8$ resins. Water was acidified to $\mathrm{pH}=2$ with concentrated $\mathrm{HCl}$, and passed through glass columns $\left(30 \times 3 \mathrm{~cm}^{3}\right)$ filled with Amberlite XAD-2 or XAD-8. Prior to the application Amberlite was extracted with methanol and acetone till light absorption $(1 \mathrm{~cm}$ cuvette, $\lambda=280 \mathrm{~nm}$ ) of the solvents was reduced to zero. The sorbed acids were eluted with $\mathrm{NH}_{3} \cdot \mathrm{H}_{2} \mathrm{O}\left(0 . \mathrm{d} \mathrm{mol} / \mathrm{dm}^{3}\right)$. The excess ammonium was removed in a rotary evaporator.

Extraction. Water was acidified to $\mathrm{pH}=2$ with concentrated $\mathrm{HCl}$ and extracted twice with isoamyl alcohol. Precipitated and concentrated, in the water/organic phase interface, humic acids were separated by means of filtration (Whatman GF/F glass fibre filter) and dissolved in $\mathrm{NH}_{3} \cdot \mathrm{H}_{2} \mathrm{O}\left(0 . \mathrm{d} \mathrm{mol} / \mathrm{dm}^{3}\right)$. The excess ammonium was removed in a rotary evaporator.

Humic acids concentration. The amount of isolated humic acids was determined gravimetrically, and recalculated to the volume of water taken for analysis. Isolation efficiencies were calculated basing on the bilance of colour (absorption at $\lambda=400 \mathrm{~nm}$ ) and dissolved organic carbon (DOC).

Physical and chemical properties of the acids. The following properties of the isolated humic acids were measured.

- molecular weight distribution (ultrafiltration, Diaflo membranes)

- ash $\left(450^{\circ} \mathrm{C}, 4 \mathrm{hr}\right)$

- elemental composition (C, H, N, S and O - as a difference)

- absorption spectra (UV, VIS, IR, ${ }^{1} \mathrm{H}-\mathrm{NMR}$ )

\section{Results and discussion}

In table 1 data characterizing the efficiencies of humic substances isolation by means of the tested methods are presented. As a measure of the efficiency light absorption $(\lambda=400$ $\mathrm{nm})-\mathrm{A}_{400}$ and concentration of dissolved organic carbon - DOC, were utilised. The overall efficiency of sorption was as follow: extraction (30 \% - DOC / $70 \%$ - $\left.\mathrm{A}_{400}\right)$, anionite (37/95), Amberlite XAD-2 (40/95), Amberlite XAD-8 (38/96), activated carbon (73/100), coprecipitation (80/32).

In the case of all tested methods, except extraction, either desorption or desalination, and/or both were necessary. This step in the isolation procedure, most often, influences the 
overall efficiency to the highest degree. It can also determine the properties of the isolated humic acids, in particular when the desorption is carried out under drastic chemical conditions. Data presented in table 1 have proven that the application of macroreticular resins secures the highest recovery of humic substances. Very efficient is also the reverse osmosis (RO). Another advantage of RO are soft conditions of the isolation. On the other hand other inorganic and organic constituents dissolved in water are coisolated with humic acids by this method, which is disadvantageous when properties of humic substances are to be further investigated. Activated carbon has proven to be the most effective sorbent of humic substances. However, desorption of humic substances from activated carbon is exceedingly troublesome. The least efficient method of humic substances recovery is coprecipitation.

The results presented in table 1 confirm data on the efficiency of humic substances isolation scattered in the literature (Aiken, 1985; Pempkowiak, 1991; Gjessing et al., 1998). Much less is known on the properties of the isolated substances, and above all on the qualitative comparison of the material isolated by various techniques. Selected properties of humic substances isolated by the tested methods are presented in table 2 .

Elemental composition. Highest ash content is found in acids which were not the subject of desalination. The same acids have the highest nitrogen content, most likely due the isolation procedure which leads to the acids isolation in the form of ammonium salts.

Absorption-spectra. Absorption spectra in the visible range prove that the aromaticity is the highest in acids recovered by means of the DEAE anionite. High content of aromatic rings is, as a rule, accompanied by low $A_{4 / 6}$ value (Schnitzer and Khan, 1972). Acids recovered with Amberlite XAD-2 are least aromatic as judged by absorption spectra in the visible range. This is confirmed by the results of ${ }^{1} \mathrm{H}-\mathrm{NMR}$ analysis. A notable exception is the RO isolated material characterized by both low $\mathrm{A}_{4 / 6}$ value (indicative of high aromaticity) and low $\mathrm{H}_{\mathrm{aro}} / \mathrm{H}_{\mathrm{oli}}$ value (low aromaticity). The contradiction is caused, most likely, by specific composition of the isolated organic matter comprising, apart from humic substances, lipids and carbohydrates (Gjessing et al., 1998).

Molecular weight. Recovered humic acids are characterized by molecular weight smaller than $10.000 \mathrm{Da}$. Proportion of acids with molecular above $15.000(18-24 \%)$ depends on the methods used for isolation.

\section{Conclusion}

The aim of the study was the evaluation of the suitability of the humic substances isolation from water procedures. Considering efficiency of procedures, the ease of purification as well as the properties of isolated acids, utilisation of macroporous resins is recommended for studies of humic substances.

\section{References}

Aiken G. (1985). Isolation and concentration techniques to aquatic humic substances. In „Humic substances in soil, sediment and water”. G. Aiken, D. McKnight and R. Wershaw eds., Wiley, New York 1985, 363-385.

Gjessing E., Alberts J., Bruchet A., Egeberg P., Lydersen E., Hogewn L., Hobed J., Munster U., Pempkowiak J., Perdue M., Ratnawera M., Rybacki D., Takes M., AbbotBrown G. (1998): Multi method characterisation of natural organic matter isolated from 
water characterisation of reverse osmosis isolates from water of two semi identical dystrophic lakes basins in Norway. Wat. Res., 32, 3108-3124.

Pempkowiak J. (1991). Comparison of Amberlite XAD-2 and XAD-8 resins as sorbents of humic substances from water. Humus untised, 3, 323-326.

Schnitzer M.. Khan S. (1972). Humic substances in the environment. Marcel Dekker, New York 1972, 327 pp.

Table 1. Efficiency of the isolation procedures

\begin{tabular}{|c|c|c|c|c|c|c|c|c|}
\hline \multirow[t]{2}{*}{ Isolation procedure } & \multicolumn{2}{|c|}{ Sorption (\%) } & \multicolumn{2}{|c|}{ Desorption (\%) } & \multicolumn{2}{|c|}{ Desalinationa $(\%)$} & \multicolumn{2}{|c|}{ Overall efficiency (\%) } \\
\hline & $\mathrm{A}_{400} *$ & DOC & $\mathrm{A}_{400}$ & $\mathrm{DOC}$ & $\mathrm{A}_{400}$ & DOC & $\mathrm{A}_{400}$ & DOC \\
\hline Extraction & - & - & - & - & - & - & 70 & 30 \\
\hline Anionite & 95 & 37 & 95 & 82 & 84 & 86 & 76 & 26 \\
\hline Activated carbon & 100 & 73 & 40 & 62 & - & - & 40 & 45 \\
\hline Amberlite XAD-2 & 95 & 40 & 88 & 85 & - & - & 84 & 34 \\
\hline Amberlite XAD-8 & 96 & 38 & 90 & 90 & - & - & 87 & 34 \\
\hline Reverse osmosis & 100 & 93 & - & - & 87 & 93 & 87 & 86 \\
\hline Coprecipitation & 80 & 32 & - & - & 43 & 52 & 33 & 17 \\
\hline
\end{tabular}

* $\mathrm{A}_{400}$ - based on colour (absorbance at $400 \mathrm{~nm}$ ) removal

DOC - based on dissolved organic carbon removal 
Table 2. Properties of the isolated humic substances

\begin{tabular}{|c|c|c|c|c|c|c|c|c|c|}
\hline \multirow{2}{*}{$\begin{array}{l}\text { Isolation } \\
\text { procedure }\end{array}$} & \multicolumn{4}{|c|}{$\begin{array}{c}\text { Elemental composition } \\
(\%)\end{array}$} & \multicolumn{3}{|c|}{ Absorption spectra* } & \multicolumn{2}{|c|}{$\begin{array}{c}\text { Molecular weight } \\
(\%)^{* *}\end{array}$} \\
\hline & Ash & $\mathrm{C}$ & $\mathrm{H}$ & $\mathrm{N}$ & $\begin{array}{c}\mathrm{A}_{4 /} \\
6\end{array}$ & $\begin{array}{c}\mathrm{A}_{2950 / 172} \\
0\end{array}$ & $\mathrm{H}_{\text {aro/alif }}$ & $\mathrm{Fr}<1000$ & $F>5000$ \\
\hline Extraction & 12 & 47.3 & 5.6 & 2.3 & 7.2 & 0.41 & 0.037 & 18 & 21 \\
\hline Anionite & 8 & 46.3 & 6.2 & 2.5 & 6.9 & 0.31 & 0.042 & 23 & 14 \\
\hline $\begin{array}{l}\text { Amberlite XAD- } \\
2\end{array}$ & 13 & 48.2 & 5.7 & 4.6 & 7.5 & 0.34 & 0.035 & 19 & 19 \\
\hline $\begin{array}{l}\text { Amberlite XAD- } \\
8\end{array}$ & 12 & 48.0 & 5.6 & 4.6 & 7.4 & 0.34 & 0.035 & 19 & 17 \\
\hline Reverse osmosis & 7 & 46.1 & 5.8 & 3.0 & 7.0 & 0.21 & 0.021 & 24 & 14 \\
\hline
\end{tabular}

* $\mathrm{A}_{4 / 6}$ - ratio of absorbances at wavelengths $465 \mathrm{~nm}$ and $665 \mathrm{~nm}$ (VIS range)

* $\mathrm{A}_{2950 / 1720}$ - ratio of absorbances of wave number $2950 \mathrm{~cm}^{-1}$ and $1720 \mathrm{~cm}^{-1}$ (IR range)

* $\mathrm{H}_{\text {aro/alif }}$ - ratio of peak areas at chemical shifts ranges 6-8 ppm and 0-4.5 ppm $\left({ }^{1} \mathrm{H}\right.$ NMR spectra)

${ }^{* *} \mathrm{Fr}<1000, \mathrm{Fr}>5000$ - content of frac 